\section{Dynamics of calcitonin gene-related peptide-like cells changes in the lungs of two-kidney, one-clip rats}

\author{
I. Kasacka, E. Arciszewska \\ Department of Histology and \\ Cytophysiology, Medical University, \\ Bialystok, Poland
}

\begin{abstract}
Taking into consideration renal hypertension-induced homeostatic disorders and the key role of calcitonin gene-related peptide (CGRP) in many, systemic functions regulating systems, a question arises as to what an extent arterial hypertension affects the morphology and dynamics of pulmonary CGRPimmunopositive cell changes. The aim of the present study was to examine the distribution, morphology and dynamics of changes of CGRPcontaining cells in the lungs of rats in the twokidney, one-clip (2K1C) renovascular hypertension model. The studies were carried out on the lungs of rats after $3,14,28,42$, and 91 days long period from the renal artery clipping procedure. In order to identify neuroendocrine cells, immunohistochemical reaction was performed with the use of a specific antibody against CGRP. It was revealed that renovascular hypertension caused changes in the neuroendocrine, CGRP-containing cells in the lungs of rats. The changes, observed in the neuroendocrine cells, depended on time periods from experimentally induced hypertension. The highest intensity of changes in the neuroendocrine cells was observed in the lungs of rats after 14 days from the surgery.
\end{abstract}

\section{Introduction}

Arterial hypertension results in ischemia of tissues and organic insufficiency, the process, occurring at both systemic and local levels. Hypertension leads to disorders of many systems and organs, causing cardiac hypertrophy, increased sclerosis development, metabolic disorders, anaemia and neurological disturbances, while local changes affect, first, vascular walls. ${ }^{1,2}$ Endothelial dysfunction is observed, as well as activation of mitogenic factors, leading to hypertrophy of tunica intima and vascular media ${ }^{3-5}$ and the production of aerobic radicals and prostaglandins is increased. ${ }^{6}$

The maintenance of arterial blood pressure within normal values is a significant link for the homeostatis controlling mechanisms, ${ }^{7}$ involving the nervous system, the kidneys, the hormonal system and many other factors, significantly controlling the motor activity of vascular walls building smooth muscle cells..$^{8-10}$ Arterial hypertension develops from disorders in arterial blood pressure controlling mechanisms and from a disturbed relationship between vasodilative and vasoconstrictive factors. $^{11}$

Regarding the pathogenesis of arterial hypertension, experimental studies prove a big role of the neuropeptides, secreted by neuroendocrine cells of the epithelium in the airways, the gastrointestinal tract and in the genitourinary tract. ${ }^{12-18}$ The calcitonin gene-related peptide (CGRP) is one of the substances, fairly significant for hypertension aetiology. ${ }^{19,20}$ CGRP participates in a number of physiological and pathological processes, including inflammatory processes, suppression of cell proliferation and cardiovascular control. ${ }^{21}$ CGRP is one of the strongest vasodilators, increasing blood flow rates in cerebral and coronary vessels, as well as in cutaneous vessels, ${ }^{22}$ exerting positive chronotropic and inotropic effects. ${ }^{23}$ CGRP-containing, afferent, sensory nerve fibres innervate blood vessel walls. ${ }^{24}$ CGRP is also localised in vascular endothelium. ${ }^{25}$ Afferent pulsation causes CGRP release from nerve endings, contributing to vasodilative effects, ${ }^{26}$ while both forms of CGRP, i.e., alphaCGRP and beta-CGRP are for this process responsible. $^{27}$

It appears from reports of many authors that CGRP plays a significant role in the initiation and progression of hypertension. ${ }^{22,27}$ It has been demonstrated that CGRP plays a protective function for endothelial cells and for smooth muscle cells. ${ }^{28,29}$ It decreases muscular layer tension, binding with an appropriate receptor or enhancing nitrogen oxide synthesis. ${ }^{30}$ Moreover, it exerts antagonistic effects on the renin-angiotensin-aldosterone (RAA) system and endothelins, demonstrating cardioprotective properties. ${ }^{31}$ Therefore, it has been assumed that CGRP plays an important role in blood pressure modulation in physiological conditions, as well as in the pathophysiology of hypertension.

CGRP is one of the peptides, secreted by the, so-called- pulmonary neuroendocrine cells (PNEC), which occur individually in airway epithelium as neuroepithelial bodies (NEB) ${ }^{32}$ It appears from a literature review that, in various pathological situations, both the number and morphology of these cells undergo certain changes, what lets assume their active participation in many processes. ${ }^{32-35}$

No data were found in the available literature, concerning CGRP-positive pulmonary cells in systemic hypertension of various aeti-
Correspondence: Prof. Irena Kasacka, Department of Histology and Cytophysiology, Medical University, Kilinski 1 str., 15-089 Bialystok, Poland. Tel/Fax: +48.85.7485516 - Tel. +48.85.7485458. E-mail: kasacka@umwb.edu.pl

Key words: CGRP-positive cells, lung, hypertension (two-kidney one-clip), rat.

Received for publication: 4 November 2011. Accepted for publication: 24 January 2012.

This work is licensed under a Creative Commons Attribution NonCommercial 3.0 License (CC BYNC 3.0).

(C) Copyright I. Kasacka and E. Arciszewska, 2012 Licensee PAGEPress, Italy

European Journal of Histochemistry 2012; 56:e10 doi:10.4081/ejh.2012.e10

ology. Taking into account that fact, it was decided to evaluate the dynamics of changes in the numbers of CGRP-positive pulmonary cells in rats with renovascular hypertension.

\section{Materials and Methods}

\section{Experimental animals}

All the procedures involving the animals and their care were conducted in conformity with the institutional guidelines that are in compliance with national and international law and with guidelines for the use of animals in biomedical research. ${ }^{36}$

Study assumptions, aim, schedule and mode of animal treatment were approved by the Senate Committee for Supervision of Experiments on Humans and Animals, Medical University of Bialystok, Poland.

The study was performed on fifty (50) young male Wistar rats, their body weight at the beginning of the experiment remaining within $160-180 \mathrm{~g}$ (mean body weight: $170 \pm 10 \mathrm{~g}$ ). The rats were housed in lighted and ventilated conditions with room temperature and regular day/night rhythm. The animals had a free access to standard granulated chow and drinking water was available ad libitum. All the experiments were performed at the same time of the day.

After 1 week of acclimatization, the systolic blood pressure (SBP) was measured in each rat was measured and the renovascular hypertension inducing procedure was performed.

\section{Two-kidney, one-clip renovascular hypertension}

After the rats were anesthetized by exposure to pentobarbital ( $40 \mathrm{mg} / \mathrm{kg}$, i.p.), a $3-\mathrm{cm}$ retroperitoneal flank incision was performed 
under sterile conditions. The left kidney was exposed and the renal artery was carefully dissected free of the renal vein. The renal artery was then partially occluded by placing a silver clip with an internal diameter of $0.20 \mathrm{~mm}$ on the vessel. The wound was closed with a running 3-0 silk suture $(n=30)$. Sham operated rats $(n=20)$ had identical surgery except artery clipping.

\section{Histology}

Method of experimental material collection and fixation

After 3, 14, 28, 42 and 91 days from the renal artery clipping procedure, the rats (six examined and four controls) were anaesthetized with pentobarbital (50 mg/kg b.w.) and sacrificed by decapitation. Following thoracotomy, the lungs were collected in whole. Immediately after the preparation of the collected organs, Bouin's fluid was administered by syringe into the trachea to smooth the pulmonary pleura in the right lung. Following the trachea ligation, the lung was fixed in Bouin's fluid for $24 \mathrm{~h}$ at $4^{\circ} \mathrm{C}$. Then, following lobectomy from circumference to the hilus, the anterior part of the superior pulmonary lobe was routinely placed in paraffin blocks and then sectioned by a Leica 2025 rotating microtome. The paraffin blocks were cut into $4 \mu \mathrm{m}$ sections and attached to positively charged glass slides.

\section{Identification of endocrine cells by}

immunohistochemical methods

In the immunohistochemical study, the EnVision method was used, according to Herman and Elfont. ${ }^{37}$ An immunohistochemical reaction was run on the paraffin lung sections of the studied animals, searching for the calcitonin gene-related peptide in neuroendocrine cells. In those studies, a specific antibody against CGRP was applied (Cat. No C 8198, in 1:8000 dilution, Sigma-Aldrich, Saint Louis, M0, USA). The antiserum was diluted in an antibody diluent (S 0809, Dako Cytomation, Glostrup, Denmark).

\section{Immunohistochemical reaction procedure}

Paraffin-embedded sections were deparaffinized and hydrated in pure alcohols, then pretreated in a pressure chamber, heating for 1 min at 21 psi at $125^{\circ} \mathrm{C}$ with $\mathrm{S} 2369$ target retrieval solution citrate of $\mathrm{pH} 6.0$ (Dako) for antigen retrieval. After cooling to room temperature, the sections were incubated with S 2001 peroxidase blocking reagent (Dako) for $10 \mathrm{~min}$ to block endogenous peroxidase activity. The sections were incubated overnight at $4^{\circ} \mathrm{C}$ in a humidified chamber with the diluted antibody. The antibody binding was visualized with support of an EnVision Kit (K 4011, Dako) with labelled polymer-HRP anti-rabbit. The bound antibodies were visualized by 1-min incubation with liquid 3,3'-diaminobenzidine substrate chromogen. The sections were finally counterstained in Vector QS haematoxylin, mounted and evaluated under light microscope. Appropriate washing with Wash Buffer S 3006 (Dako) was performed between each step. The specificity tests, performed for the CGRP antibody, included: negative control, where the antibodies were replaced by normal rabbit serum (Vector Laboratories, Burlingame, CA, USA) at the respective dilution and positive control was obtained for specific tissue as recommended by the producer for CGRP is rat brain. The obtained results of immunohistochemical staining were submitted for evaluation in an Olympus Bx50 microscope. Cells with CGRP expression were searched for and their topography was observed.

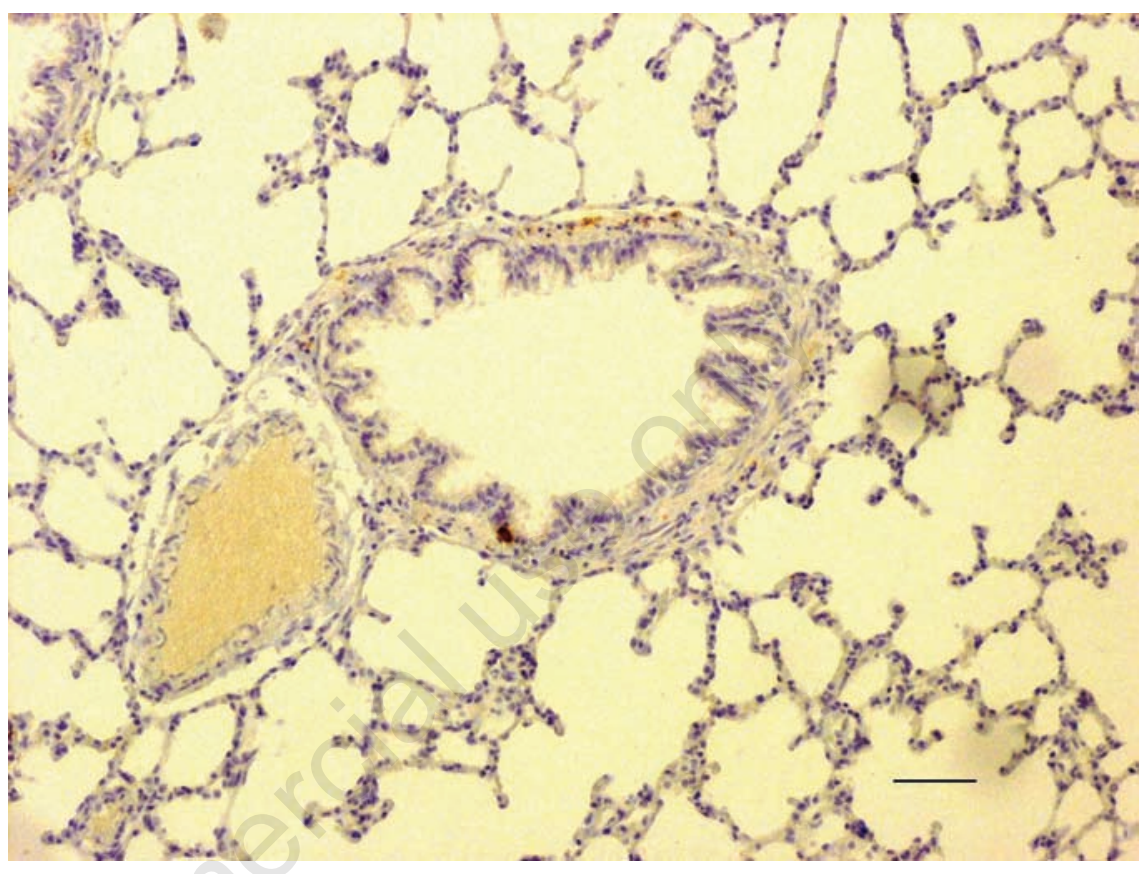

Figure 1. Single cell containing CGRP in the lung of control rat. Scale bar: $100 \mu \mathrm{m}$.

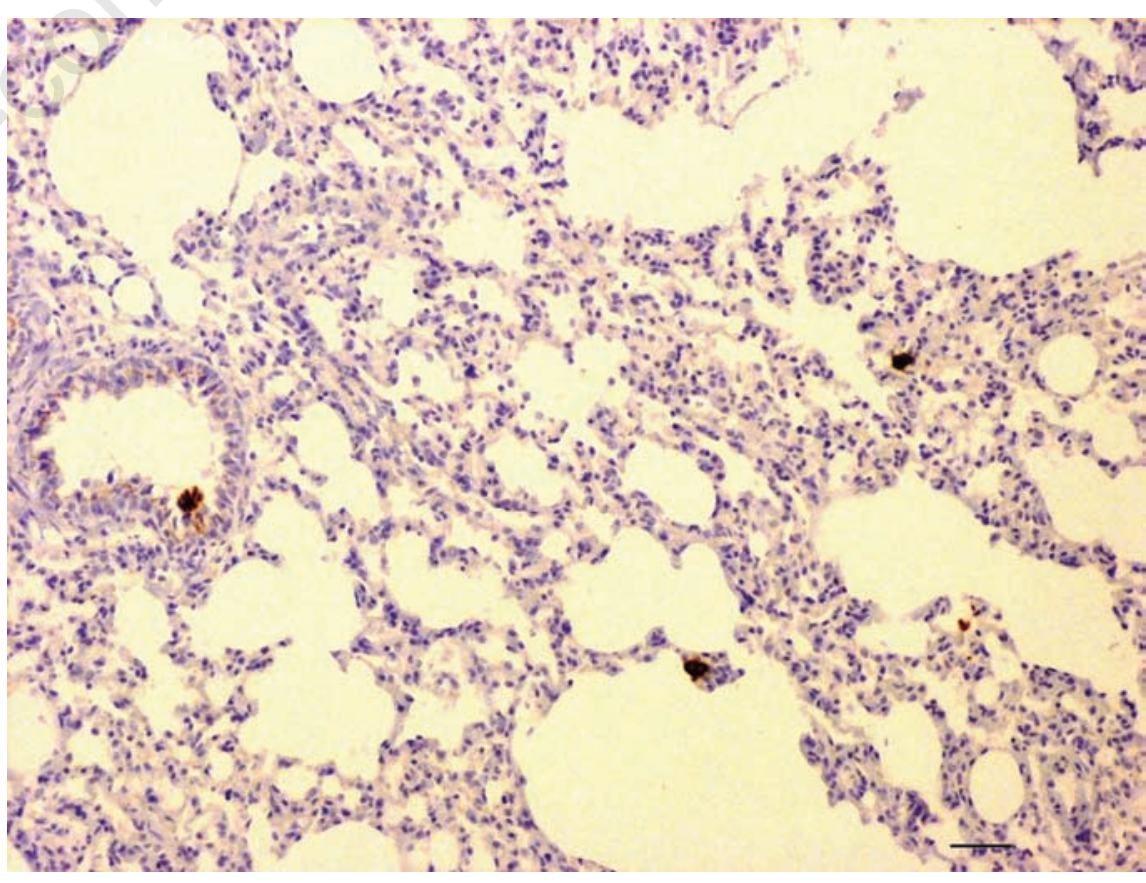

Figure 2. Small few-cell clusters of NE cells with CGRP expression in rat lungs after three days from left renal artery clipping. Scale bar: $100 \mu \mathrm{m}$. 


\section{Results}

Location, morphology and immunohistochemical characteristics of neuroendocrine cells in the lung structures of control and twokidney, one-clip rats

Following immunohistochemical reactions, the neuroendocrine (NE) cells were clearly distinguishable in structures of the analysed organs of all the studied rats. The NE cells, surrounded by other cells of the respiratory tract epithelium, were distinct by dye and shape, the latter ranging from pyramidal to polygonal, oval or columnar. In the lungs of the control rats, CGRP-immunopositive cells occurred in the respiratory tract as scattered, single or as intraepithelial, small groups (most often 2-3 cells only). The highest number of NE cells with positive reaction to the antibodies against CGRP was observed in larger bronchia, while the smallest PNE cell numbers occurred in alveolar ducts and alveoli. The intensity of immunohistochemical reaction to anti-CGRP antibodies was moderate in the PNEC of control rats (Figure 1).

After three days from artery clipping, the number and localization of CGRP-immunoreactive cells in the lungs of the rats were similar to their control counterparts. A higher number of NE cells, grouped in small, few-cell clusters of PNEC, was the only visible difference. The intensity of immunohistochemical reaction was also similar to that observed in the control rats (Figure 2).

Two weeks after the left renal artery clipping, clearly higher numbers of cells with positive reaction to anti-CGRP antibodies were found in the rats with experimentally induced hypertension vs. control animals. Single NE cells, as well as NEBs, were localised at various levels of the respiratory tracts of studied rats.

The most numerous NE cells, observed in the epithelium of bronchi, where CGRPimmunopositive cells, frequently grouped into large, multicellular clusters of PNE cells. Higher numbers of CGRP-immunopositive cells were also found in the lungs of rats in that group vs. the other groups. Some CGRPimmunopositive cells were also found at the level of the alveolar ducts and of the alveoli (Figure $3 \mathrm{~A}, \mathrm{~B}$ ).

The strongest immunoreactivity of PNE cells, both single and in small clusters, as well as in large NEBs, was observed after 2 weeks from the clipping procedure. After 28 days from clipping, the number of NE cells with CGRPimmunopositive reaction was slightly smaller in the studied lungs, comparing to that in the previous group animals. Cells with a positive reaction to the anti-CGRP antibodies were found in the respiratory tract, most often as scattered, single NE cells or in small, severalcell clusters of NE cells (Figure 4). NEBs, with higher numbers of NE cells, were identified only sometimes and with a weaker expression of CGRP, when compared to the previous animal group.

The number and localisation of CGRPimmunoreactive cells in the lungs of the rats after 42 and 91 days from the left renal artery clipping were similar and comparable to those in the animals after three days from clipping. Most of the CGRP-immunopositive cells, which were observed in the respiratory tract, included single NE cells, while small, several-cell clusters of PNE cells were observed in the bronchia and bronchioli of rats in those experimental groups (Figure 5). The immunoreactivity of PNE cells, both single and clustered, was rather moderate.
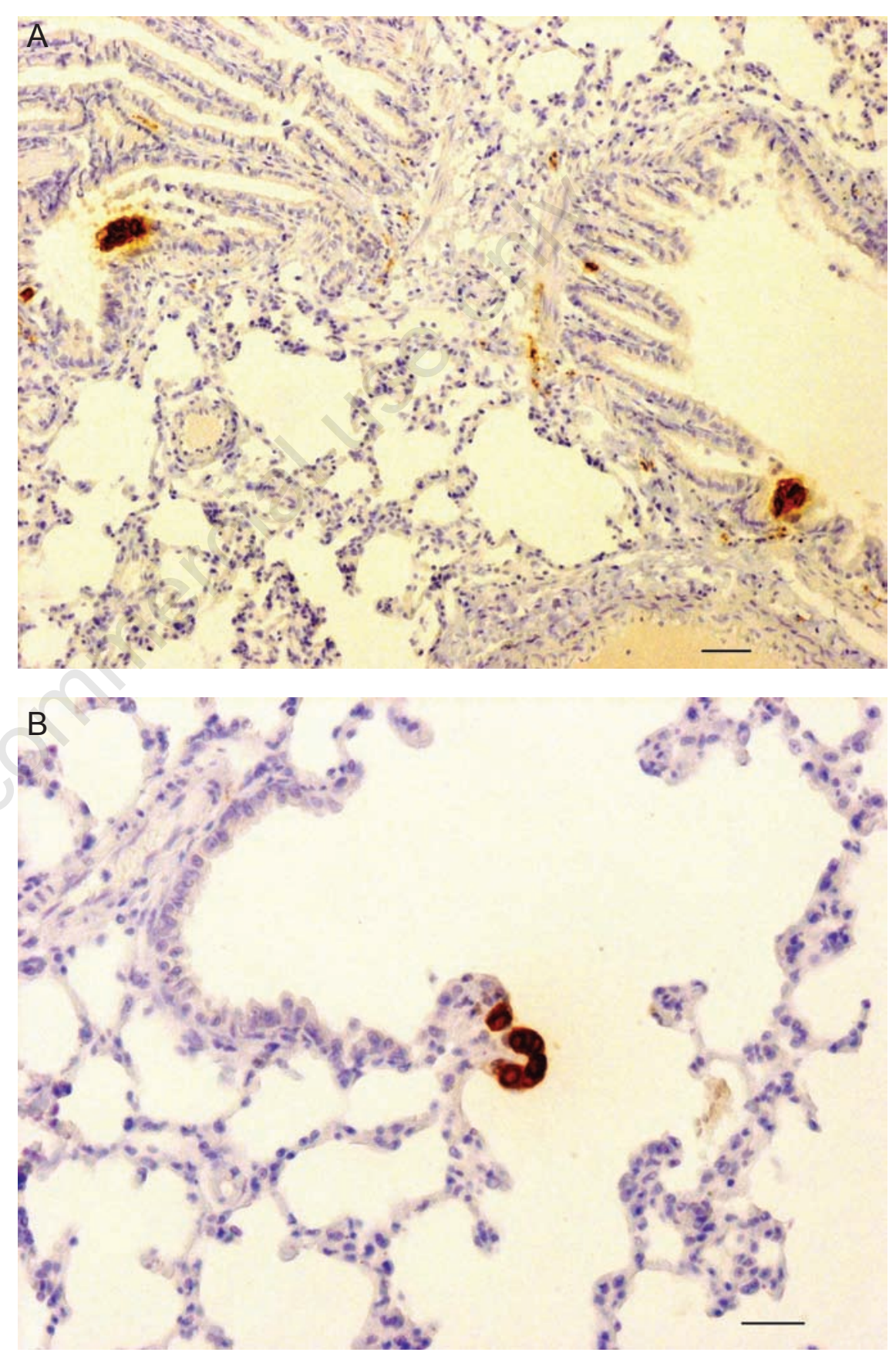

Figure 3. A) Multicellular clusters of PNE cells with strong CGRP expression in the cytoplasm; scale bar: $100 \mu \mathrm{m}$. B) Rat lungs after 14 days from the left renal artery clipping; scale bar: $50 \mu \mathrm{m}$. 


\section{Discussion}

Topographic distribution and the occurrence of CGRP-immunoreactive endocrine cells were studied in lungs of hypertensive rats.

The pathogenesis of arterial hypertension is complex and multifactorial in character. Arterial blood pressure control is a very complex process, involving various organs and systems: the kidneys with the RAA system, the neurohormonal system with participation of catecholamines, vasopressins and the nervous system., ${ }^{4,10,38}$ There is strong interdependence and a mutual linkage among many mechanisms and blood pressure controlling factors. Despite the big progress, which, so far, can be perceived in the pathophysiology of arterial hypertension, it is still not known, which of these factors play a decisive role in hypertension formation and development.

Arterial hypertension rarely occurs as isolated condition. In many cases, hypertension is accompanied by medical conditions, which are, most often, its complications. It seems that, from the clinical point of view, the most significant complications are those that cause certain changes in the cardiovascular system. Neuropeptides, like CGRP, play an integral role in the pathophysiology of hypertension. CGRP participates in the regulation of vascular tone and regional organ blood flow, what was demonstrated in many experimental data, as well as observed in a number of clinical studies. ${ }^{20,21,39-41}$

CGRP-containing nervous fibers are localised on the borderline between the tunica adventitia and media myocytes. CGRP receptors are widely distributed in the cardiovascular system. ${ }^{42}$ For this reason, CGRP receptors constitute a powerful effector system for the regulation of vascular tone and regional blood flow. It appears from studies of many authors that both CGRP and/or CGRP receptor expression increase in hypertension. ${ }^{38,40} \mathrm{~A}$ blockade of CGRP receptors in various experimental models caused an evident increase of arterial hypertension. ${ }^{38,43}$

Potassium and calcium ions play a meaningful role in the pathology of hypertension. ATP (K ATP)-dependent potassium channels are observed in endothelial cells and smooth muscle cells of vessels, the channels being a component of tonic vasorelaxation in general and local circulation. Potassium channels are the main cell membrane potential determining elements and, in consequence, they take part in vascular wall tension control. Potassium channel opening by factors, released from the endothelium, e.g., nitrogen oxide (NO), prostacyclin (PGI2), leads to flows of potassium ions outwards from the cell inside, resulting in hyperpolarisation, closure of potential-depend- ent membranous calcium channels and dilation of blood vessels. In turn, potassium channel closure with calcium channel opening, leads to depolarisation and contraction. ${ }^{44}$ Disturbed functions of potassium channels are at the base of hypertension pathogenesis. The potassium channels, which selectively filter potassium ions, exert their effects on the membranous potential of smooth muscle cells. CGRP stimulates these channels, leading to hyperpolarisation of the membranes of vascular smooth muscle cells. ${ }^{45}$

The results of our earlier studies demonstrate that experimentally induced renovascular hypertension in rats exerts a huge effect on CGRP-positive cells in the lungs. A clear

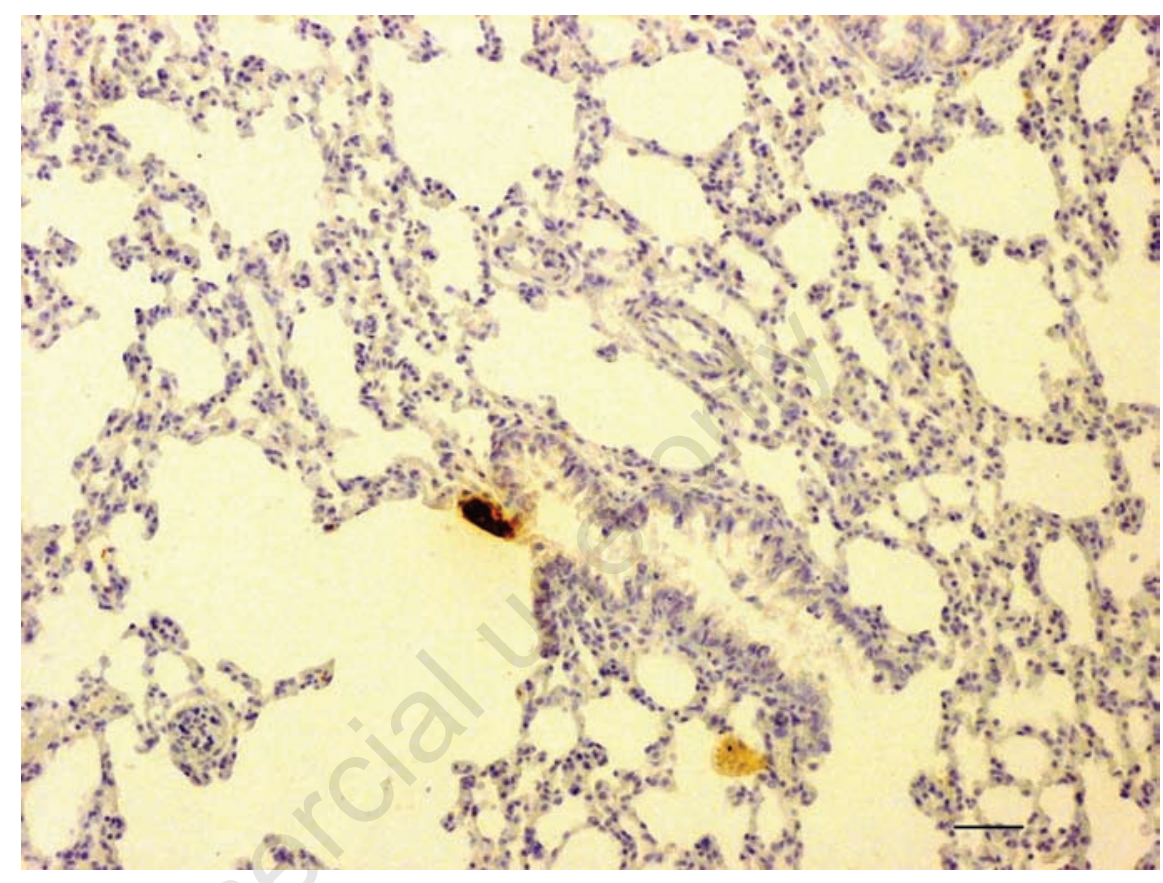

Figure 4. CGRP immunolabelling in the cytoplasm of NE cells (dark-colored granules) in the lung of $2 \mathrm{~K} 1 \mathrm{C}$ rat after 28 days from clipping. Scale bar: $100 \mu \mathrm{m}$.

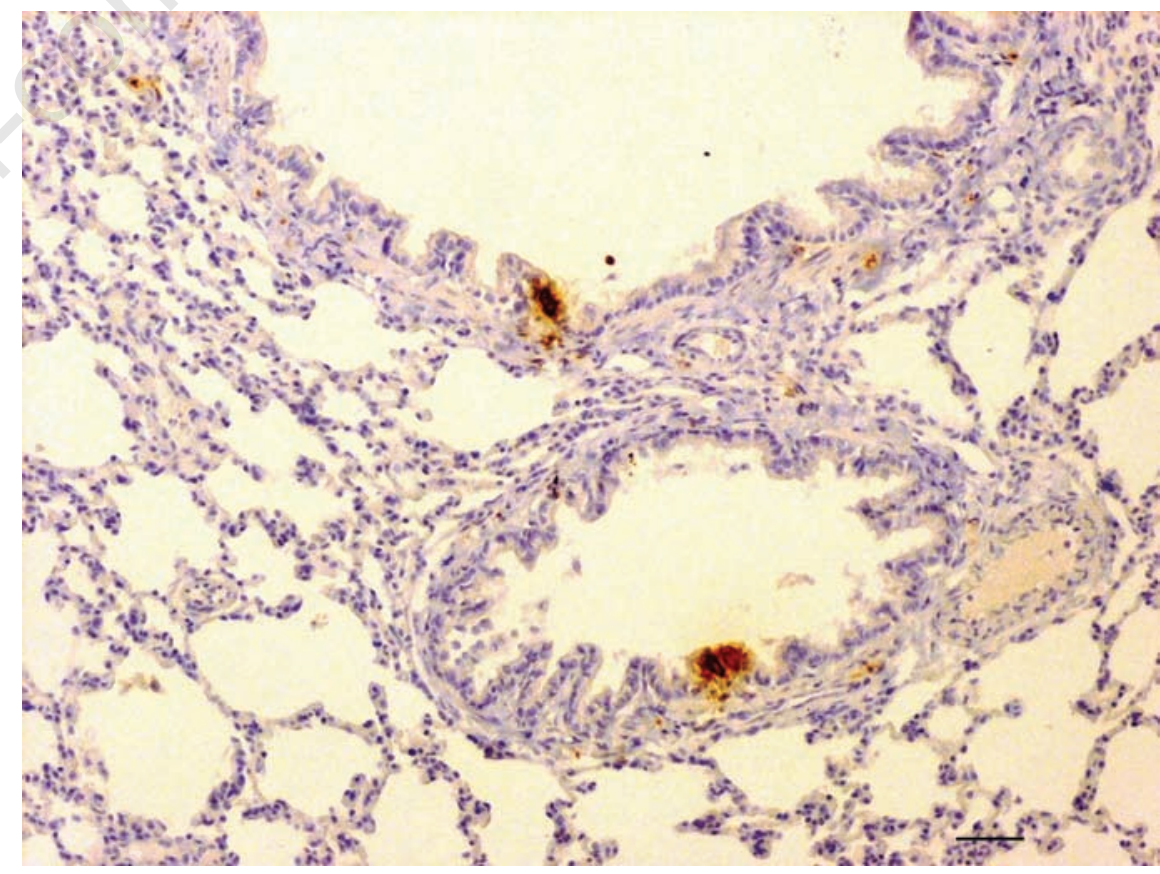

Figure 5. CGRP-immunopositive cells in the lung of $2 \mathrm{~K} 1 \mathrm{C}$ rat after 42 days from clipping. Scale bar: $100 \mu \mathrm{m}$. 
increase in the number of CGRP-immunoreactive cells was observed in the studied animals, the cells being either single or clustered into neuroepithelial bodies in various sections of the airways. A considerable increase in the number of those cells was found after 14 days of hypertension. Then, after 28 subsequent days, the number of CGRP-positive cells was minimally lower than in the animals after the two-week duration of the experiment. While after 42 and 91 days from the study, the animals demonstrated decreased numbers of those cells, down to the level observed in the lungs of the animals on the third day of the hypertensive period.

Hyperplasia of CGRP-immunoreactive cells was noted in neonatal rats with congenital diaphragmatic hernia, ${ }^{46}$ carcinoid tumours ${ }^{32}$ and in cigarette smokers. ${ }^{47}$ It was previously stated that the production and release of neuropeptides could significantly be altered in several models of experimental hypertension. ${ }^{48-50}$ No data were found in the available literature concerning the increasing number of airway CGRP-containing neuroendocrine cells in the conditions of renovascular hypertension. Therefore, it is rather difficult to explain the cause of the increasing quantity of pulmonary, CGRP-immunoreactive cells, as observed in hypertension.

Stenosis of the renal artery mobilises the RAA system. An ischaemic kidney produces excessive renin volumes, that consequently results in an increased secretion of pressively and mitogenically acting angiotensin II. $^{5}$ An increased blood pressure causes reduced oxide supplementation to the lungs, while impairing the gas exchange. Additionally, hypoxia significantly leads to contraction of pulmonary blood vessels. Chronic oxygen deficiency increases the number of neuroendocrine cells in the airways. ${ }^{15,51}$ It is confirmed by Keith's studies, who, in conditions of one-day hypoxia, observed hyperplasia of cells with 5-HT expression in rat foetuses. CGRP dilates pulmonary blood vessels, reducing the effect of chronic hypoxia. ${ }^{52}$ The role of CGRP in hypertension is not clear. CGRP administration decreases blood pressure both in animals and in people. ${ }^{23,50}$ Clinical studies have indicated that, in patients with systemic hypertension, the levels of circulating CGRP may be decreased, increased or unchanged, ${ }^{22,53}$ while in hypertensive rats, the level of CGRP increases both in vivo and in vitro conditions. ${ }^{50,54}$

In hypertension, regardless of its aetiology, it comes to remodelling of blood vessels; these changes include hyperplasia of the muscular coat, fibrosis involves the tunica intima and the tunica adventitia, what results in increased peripheral resistance. ${ }^{55}$ Cogo et al. found muscularisation of pulmonary vessels and proliferation of fibroblasts in various oxy- gen conditions. ${ }^{56}$ In hypertensive lungs of the experimental animals, thickened vascular media was observed, as well as big amounts of connective tissue, both in tunica intima and tunica adventitia. The observed morphological changes were accompanied by an increased number of single CGRP-positive cells and of neuroepithelial bodies, as well as by hyperplasia of NEBs, especially after two weeks of hypertension. However, it is still an open question why the cells increase in their numbers in the lungs of animals with renovascular hypertension.

The mean half-life of CGRP in plasma is relatively short, amounting to approximately 10 $\min$, then it undergoes inactivation with the participation of tryptase and chymotrypsin. ${ }^{57}$ Therefore, it should be supposed that PNEC hyperplasia, which was found in those studies, is a CGRP deficit compensation mechanism. The lungs in physiological and pathological conditions are subject of complex control processes, in which nervous and hormonal factors play a significant role, tailoring their functions to the actual load of the system. There are also local control mechanisms, which integrate the elements of the airway functions, including, by all means, the peptide, associated with calcitonin gene, i.e., CGRP. There are many factors responsible for the control of CGRP expression and release. Locally produced factors, such as bradykinin and prostaglandins ${ }^{58,59}$ endothelin and the sympathetic nervous system, ${ }^{58}$ as well as the nerve growth factor (NGF) reveal high physiological significance in pulmonary flow control. ${ }^{60,61}$ It has been shown that NGF is a stimulant of CGRP mRNA synthesis. NGF would decrease blood pressure through the stimulation of CGRP synthesis and release ${ }^{61}$ The study suggested that bradykinin effects resulted from the cyclo-oxygenase mediated increase in prostaglandin production..$^{59}$ It may be assumed that those relationships can be the cause or one of the causes of CGRP release. ${ }^{6,62}$ Probably, these factors alter acute releases of CGRP and can also modulate long-term production of this peptide.

An increased number of CGRP immunopositive cells may be a consequence of disturbed secretion of the peptide, what has been confirmed by Gosney's studies. ${ }^{46}$ He found an increased quantity of CGRP-positive cells in rats with nitrofen-induced diaphragmatic hernia, which was an effect of the suppressed release of the peptide; which, in turn, predisposes to hypertension development, characteristic for this disease.

A number of pathological pulmonary conditions are accompanied by PNEC hyperplasia, which may result either from their mitotic divisions or from post-mitotic differentiation of non-endocrine cells; $; 33,64$ however, this prob- lem has still been awaiting its final solution. Antihypertensive effects of CGRP may result from the activation of neuroendocrine cells to synthesis and release of this neuropeptide and/or from an increased sensitivity of the vessels to CGRP activity. ${ }^{20,27}$

Hypertension-induced end organ damage is one of the most severe and common consequences of increased blood pressure. Since CGRP has such potent biological effects on the lung suggesting that peptide is an endogenous organ-protective agent and has important role in the regulation of lung blood flows. The primary mechanism responsible for control pulmonary flow can be arterial dilation. CGRP can significantly weaken the pathological effects of chronic pulmonary hypertension. Another possible hypothesis is that the regulation of lung blood flows can be mediated by an up-regulation of CGRP synthesis and release, or through an enhanced sensitivity of the vascular to the dilator effects of this peptide.

In the future, it is hoped that dissection of the mechanisms that control CGRP production and its actions will provide novel therapeutic targets for hypertension and other pathologies.

\section{References}

1. Przewlocki T, Kabłak-Ziembicka A, Tracz W, Kozanecki A, Kopec G, Rubis P, et al. Renal artery stenosis in patients with coronary artery disease. Kardiol Pol 2008;66:856-62.

2. Imiela J. Renal artery stenosis renovascular hypertension ischaemic nephropathy. Kardiologia na co Dzien 2009;4:21-7.

3. Kokot F, Kokot J. Renovascular hypertension - a persistently difficult diagnostic problem. Post Hig Dośw 1994;48:645-61.

4. Dzielińska Z, Januszewicz A, Demkow M, Makowiecka-Cieśla M, Prejbisz A, Naruszewicz M, et al. Cardiovascular risk factors in hipertensive patients with coronary artery disease and coexisting renal artery stenosis. J Hypertens 2007;25:66370.

5. Zellert T. Renal artery stenosis. Curr Treat Options Cardiovasc Med 2007;9:90-9.

6. Jackson EK, Branch RA, Oates JA. Participation of prostaglandins in the control of renin release. In: JA Oates (ed.) Prostaglandins and the cardiovascular system, pp 255-76. 1982, Raven Press, New York, USA.

7. Dockray GI. The G.W. Harris Prize Lecture. The gut endocrine system and its control. Exp Physiol 1994;79:607-34.

8. Aurell M, Jensen G. Treatment of renovascular hypertension. Nephron 1997;75:37383. 
9. Narkiewicz K. The role of the sympathetic nervous system in the development of hypertension and its complications. Post Nauk Med 2002;15:123-8.

10. Textor SC. Renovascular hypertension and ischemic nephropathy. In: BM Brenner (ed.) The kidney, pp. 1528-66. 2008, Saunders, Philadelphia, USA.

11. Biegelsen ES, Locsalzo J. Endothelial function and atherosclerosis. Coron Artery Dis 1999;10:241-56.

12. Johnson DE, Georgieff MK. Pulmonary endocrine cells Their secretory products and their potential roles in health and chronic lung disease in infancy. Am Rev Respir Dis 1989;140:1807-12.

13. Giad A, Polak J, Gaitonde V, Hamid Q, Mososo G, Legon S, et al. Distribution of endothelin-like immunoreactivity and mRNA in the developing and adult human lung. Am J Respir Cell Mol Biol 1991;4:50 8.

14. Schindler MB, Bohn DJ, Bryan AC, Cutz E, Rabinovitch M. Increased respiratory system resistance and bronchial smooth muscle hypertrophy in children with acute postoperative hypertension. Am J Respir Crit Care Med 1995;152:1347-52.

15. Fu XW, Nurse CA, Wong V, Cutz E. Hypoxia - induced secretion of serotonin from intact pulmonary neuroepithelial bodies in neonatal rabbit. J Physiol 2002;539:503-10.

16. Kasacka I, Majewski M. An immunohistochemical study of endocrine cells in the stomach of hypertensive rats. J Physiol Pharmacol 2007;58:469-78.

17. Zwirska-Korczala K, Konturek SJ, Sodowski M, Wylezol M, Kuka D, Sowa P, et al. Basal and postprandial plasma levels of PPY, ghrelin, cholecystokinin, gastrin and insulin in women with moderate and morbit obesity and metabolic syndrome. J Physiol Pharmacol 2007;58:13-35.

18. Kasacka I, Majewski M. Can doxazosin inhibit the hypertension-induced changes of endocrine cells in the stomach of spontaneously hypertensive rats. J Physiol Pharmacol 2008;59:189-201.

19. Doggrell SA. Migraine and beyond: cardiovascular therapeutic potential for CGRP modulators. Expert Opin Investig Drugs 2001;10:1131-8.

20. Márquez-Rodas I, Longo F, Rothlin RP, Balfagón G, Pathophysiology and therapeutic ossibilities of calcitonin gene-related peptide in hypertension. J Physiol Biochem 2006;62:45-56.

21. Brain SD, Grant AD. Vascular actions of calcitonin gene-related peptide and adrenomedullin. Physiol Rev 2004;84:90334 .

22. Portaluppi F, Trasforini G, Margutti A, Vergnani L, Ambrosio MR, Rossi R, et al.
Circadian rhythm of calcitonin gene-related peptide in uncomplicated essential hypertension. J Hypertens 1992;10:122734.

23. DiPette DJ, Schwarzenberger K, Kerr N, Holland OB. Dose dependent systemic and regional hemodynamic effects of calcitonin gene-related peptide. Am J Med Sci 1989;297:65-70.

24. van Rossum D, Hanisch UK, Quirion R. Neuroanatomical localisation, pharmacological characterisation and functions of CGRP, related peptides and their receptor. Neurosci Biobehav Rev 1997;21:649-78.

25. Doi Y, Kudo H, Nishino T, Kayashima K, Kiyonaga H, Nagata T, et al. Synthesis of calcitonin gene-related peptide by rat arterial endothelial cells. Histol Histopathol 2001;16:1073-9.

26. Peroutka SJ. Neurogenic inflammation and migraine: implications for the therapeutics. Mol Interv 2005;5;304-11.

27. Luo XL, Yang TL, Chen XP, Li YJ. Association of CALCA genetic polymorphism with essential hypertension. Chin Med J 2008;121:1407-10.

28. Deng PY, Li YJ. Calcitonin gene-related peptide and hypertension. Peptides 2005;26:1676-85.

29. Zhou Z, Peng J, Wang CJ, Li D, Li TT, Hu $\mathrm{CP}$, et al. Accelerated senescence of endothelial progenitor cells in hypertension is related to the reduction of calcitonin gene-related peptide. J Hypertens 2010;28:931-39.

30. Brain SD, Williams TJ, Tippins JR, Monis IR, MacIntyre L. Calcitonin gene-related peptide is a potent vasodilator. Nature 1985;313:54-6.

31. Huang R, Karve A, Shah I, Bowers MC, DiPette DJ, Supowit SC, et al. Deletion of the mouse alpha-calcitonin gene-related peptide gene increases the vulnerability of the heart to schemia-reperfusion injury. Am J Physiol Heart Circ Physiol 2008;294:1291-7.

32. Gustafson I, Kidd M, Chan A, Malfe rtheiner MV, Modlin IM. Bronchopulmonary neuroendocrine tumors. Cancer 2008;113:5-21.

33. Keith IM, Tjen-A-Looi S, Kraiczi H, Ekman R. Three-week neonatal hypoxia reduces blood CGRP and causes persistent pulmonary hypertension in rats. Am J Physiol Heart Circ Physiol 2000;279:1571-8.

34. Chang B, Schachna L, White B, Wigley FM, Wise RA. Natural history of mild - moderate pulmonary hypertension and the risk factors for severe pulmonary hypertension scleroderma. J Rheumatol 2006;33:269-74.

35. Kasacka I. Calcitonin gene-related peptide expression altered in pulmonary neuroendocrine cells in an experimental model of uraemia. Eur J Histochem 2006;50:89-98.

36. Giles AR. Guidelines for the use of animals in biomedical research. Tromb Haemost 1987;58:1078-84.

37. Herman GE, Elfont EA. The taming of immunohistochemistry: the new era of quality control. Biotech Histochem 1991;66:194-9.

38. Li J, Wang DH. Development of angiotensin II-induced hypertension: role of CGRP and its receptor. J Hypertens 2005;23:113-8.

39. Shioi A, Nishizawa Y. Pathophysiological roles of PTH, PTHrP, and CGRP in hypertension. Nippon Rinsho Jap J Clin Med 2000;58:477-80.

40. Lind H, Edvinsson L. Enhanced vasodilator responses to calcitonin gene-related peptide (CGRP) in subcutaneous arteries in human hypertension. J Hum Hypertens 2002;16:53-9.

41. Kasacka I. Quantitative distribution and localization of calcitonin gene-related peptide-like cells in the stomach of two kidney, one clip rats. J Physiol Pharmacol 2009;60:35-9.

42. Wimalawansa SJ. Calcitonin gene-related peptide and its receptors: molecular genetics, physiology, patophysiology and therapeutic potentials. Endocr Rev 1996;17:53385.

43. Wang Y, Wang DH. Prevention of endothelin-1-induced increases in blood pressure: role of endogenous CGRP. Am J Physiol Heart Circ Physiol 2004;287:1868-74.

44. Teramoto N. Physiological roles of ATPsensitive $\mathrm{K}+$ channels in smooth muscle. $\mathrm{J}$ Physiol 2006;572:617-24.

45. Fu XW, Nurse C, Cutz E. Characterization of slowly inactivating $\mathrm{KV} \alpha$ current in rabbit pulmonary neuroepithelial bodies: effect of hypoxia and nicotine. Am J Physiol Lung Cell Mol Physiol 2007;293: 892-902.

46. Gosney JR, Okoye B0, Lloyd DA, Losty PD Pulmonary neuroendocrine cells in nitrofen-induced diaphragmatic hernia and the effect of prenatal glucocorticoids. Pediatr Surg Int 1999;15:180-3.

47. Aquayo SM. Determinants of susceptibility to cigarette smoke. Potential roles for neuroendocrine cells and neuropeptides in airway inflammation, airway wall remodeling, and chronic airway obstruction. Am J Respir Crit Care Med 1994;149:1692-8.

48. Supowit SC, Guraraj A, Ramana CV, Westlund KN, DiPette DJ. Enhanced neuronal expression of calcitonin gene-related peptide in mineralocorticoid-salt hypertension. Hypertens 1995;25:1333-8.

49. Supowit SC, Zhao H, Hallman DM, DiPette DJ. Calcitonin gene-related peptide is a depressor in subtotal nephrectomy hyper- 
tension. Hypertens 1998;31:391-6.

50. Yamada M, Ishikawa T, Fujimori A, Miyauchi T, Goto K. Enhanced depressor and hyperaemic responses to calcitonin gene-related peptide in spontaneously hypertensive rats. Peptides 1998;19:697706.

51. Fu XW, Nurse CA, Cutz E. Expression of functional purinergic receptors in pulmonary neuroepithelial bodies and their role in hypoxia chemotransmission. Biol Chem 2004;385:275-84.

52. Keith IM, Will JA. Hypoxia and the neonatal rabbit lung: neuroendocrine cell numbers, 5-HT fluorescence intensity and relationship to arterial thickness. Thorax 1981;36:767-73.

53. Masuda A, Shimamoto K, Mori Y, Nakagawa M, Ura N, limura 0. Plasma calcitonin gene-related levels in patients with various hypertensive disease. J Hypertens 1992;10:1499-504.

54. Tomobe YI, Ishikawa T, Goto K. Enhanced endothelium-independent vasodilator response to calcitonin gene-related peptide in hypertensive rats. Eur J Pharmacol
1998;351:351-5.

55. Moundgil R, Michelakis ED, Archer SL. Hypoxic pulmonary vasoconstriction. J Appl Physiol 2005;98:390-403.

56. Cogo A, Napolitano G, Michoud MC, Barbon RD, Ward M, Martin JG. Effect of hypoxia on rat airway muscle cell proliferation. J Appl Physiol 2003;94:1403-9.

57. Bell D, McDermott BJ. Calcitonin generelated peptide in the cardiovascular system: characterization of populations and their (patho)physiological significance. Pharmacol Rev 1996;48:253-88.

58. Kawasaki H, Nuki C, Saito A. Adrenergic modulation of calcitonin gene-related peptide (CGRP) containing nerve-mediated vasodilation in the rat mesenteric resistance vessels. Brain Research 1990;506:287-92.

59. Supowit SC, Hallman DM, Zhao H, DiPette DJ. Bradykinin regulates neuronal calcitonin gene-related peptide expression and release. Hypertension 1995;26:564.

60. Lindsay RM, Lockett C, Sternberg J. Neuropeptide expression in cultures of adult sensory neurons: modulation of sub- stance $\mathrm{P}$ and calcitonin gene-related peptide levels by nerve growth factor. Neuroscience 1989;33:53-65.

61. Supowit SC, Zhao H, DiPette DJ. Nerve growth factor enhances calcitonin generelated peptide expression in the spontaneously hypertensive rat. Hypertens 2001;37:728-32.

62. Supowit SC, Hallman DM, Zhao H, DiPette DJ. Alpha2-adrenoreceptor activation inhibits neuronal calcitonin gene-related peptide expression. Brain Research 1998;782:184-93.

63. Hoyt RF, McNelly NA, Sorokin SP. Dynamics of neuroepithelial body (NEB) formation in hamster lung: light microscopic autoradiography after $3 \mathrm{H}$-thymidine labeling in vivo. Anat Rec 1990;227: 340-50.

64. Montuenga LM, Springall DR, Winter RJ, Gaer J, Zhao I, McBride JT, et al. CGRPimmunoreactive endocrine cell proliferation in normal and hypoxic rat lung studied by immunocytochemical detection of incorporation of 5 '-bromodeoxyuridine. Cell Tissue Res 1992;268:9-15. 